\title{
In situ visualization of bacterial populations in coral tissues: pitfalls and solutions
}

Naohisa Wada ${ }^{1,2,3}$ ， Frederic J Pollock ${ }^{2,3,4,5,6}$, Bette L Willis ${ }^{3,5,6}$, Tracy Ainsworth ${ }^{5}$, Nobuhiro Mano ${ }^{1}$, David G Bourne Corresp. 2,3,6

${ }^{1}$ Department of Marine Science and Resources, College of Bioresource Science, Nihon University, Fujisawa, Kanagawa, Japan

2 Australian Institute of Marine Science, Townsville, QLD, Australia

3 AIMS@JCU, Townsville, Queensland, Australia

4 Eberly College of Science, Department of Biology, Pennsylvania State University, University Park, Pennsylvania, United States

${ }^{5}$ ARC Centre of Excellence for Coral Reef Studies, James Cook University of North Queensland, Townsville, Queensland, Australia

${ }^{6}$ College of Science and Engineering, James Cook University of North Queensland, Townsville, Queensland, Australia

Corresponding Author: David G Bourne

Email address: d.bourne@aims.gov.au

In situ visualization of microbial communities within their natural habitats provides a powerful approach to explore complex interactions between microorganisms and their macroscopic hosts. Specifically, the application of fluorescence in situ hybridization (FISH) to simultaneously identify and visualize diverse microbial taxa associated with coral hosts, including symbiotic algae (Symbiodinium), Bacteria, Archaea, Fungi and protists, could help untangle the structure and function of these diverse taxa within the coral holobiont. However, the application of FISH approaches to coral samples is constrained by nonspecific binding of targeted rRNA probes to cellular structures within the coral animal tissues (including nematocysts, spirocysts, granular gland cells within the gastrodermis and cnidoglandular bands of mesenterial filaments). This issue, combined with high autofluorescence of both host tissues and endosymbiotic dinoflagellates (Symbiodinium), make FISH approaches for analyses of coral tissues challenging. Here we outline the major pitfalls associated with applying FISH to coral samples and describe approaches to overcome these challenges. 
1 Title: In situ visualization of bacterial populations in coral tissues: pitfalls and solutions

3 Authors: Naohisa Wada ${ }^{1,2,5}$, F. Joseph Pollock $2,3,4,5,6$, Bette L. Willis ${ }^{3,4,5}$, Tracy Ainsworth ${ }^{4}$,

4 Nobuhiro Mano ${ }^{1}$ and David G. Bourne 2,3,5

5

$6 \quad{ }^{1}$ Department of Marine Science and Resources, College of Bioresource Science, Nihon

7 University, Fujisawa, Kanagawa 252-0880 Japan

$8{ }^{2}$ Australian Institute of Marine Science, Townsville, QLD 4810, Australia

$9{ }^{3}$ College of Science and Engineering, James Cook University, Townsville, QLD 4811, Australia

$10{ }^{4}$ ARC Centre of Excellence for Coral Reef Studies, James Cook University, Townsville, QLD

11 4811, Australia

12 5 AIMS@JCU, Townsville, QLD 4811, Australia

$13{ }^{6}$ Pennsylvania State University, Eberly College of Science, Department of Biology, University

14 Park, PA 16802, USA

17 Corresponding Author:

18 David Bourne

19 Australian Institute of Marine Science, PMB 3, Townsville, QLD 4810, Australia

D.Bourne@aims.gov.au 


\section{Abstract}

23 In situ visualization of microbial communities within their natural habitats provides a powerful

24 approach to explore complex interactions between microorganisms and their macroscopic hosts.

25 Specifically, the application of fluorescence in situ hybridization (FISH) to simultaneously

26 identify and visualize diverse microbial taxa associated with coral hosts, including symbiotic

27 algae (Symbiodinium), Bacteria, Archaea, Fungi and protists, could help untangle the structure

28 and function of these diverse taxa within the coral holobiont. However, the application of FISH

29 approaches to coral samples is constrained by non-specific binding of targeted rRNA probes to

30 cellular structures within the coral animal tissues (including nematocysts, spirocysts, granular

31 gland cells within the gastrodermis and cnidoglandular bands of mesenterial filaments). This

32 issue, combined with high auto-fluorescence of both host tissues and endosymbiotic

33 dinoflagellates (Symbiodinium), make FISH approaches for analyses of coral tissues challenging.

34 Here we outline the major pitfalls associated with applying FISH to coral samples and describe

35 approaches to overcome these challenges. 
37

\section{Introduction}

Corals form close symbiotic associations with a range of microorganisms, including dinoflagellate microalgae, Bacteria, Archaea and viruses, a consortium collectively termed the coral holobiont (Rohwer et al., 2002; Rosenberg et al., 2007). Coral-associated bacterial communities are known to contribute to coral holobiont fitness (Rosenberg et al., 2007) and disruptions in coral-associated bacterial community structure have been implicated in the onset of coral disease (Bourne et al., 2009; Bourne, Muirhead \& Sato, 2011). However, the identification of specific bacterial pathogens directly responsible for disease causation has been problematic and, in many cases, causative agents have not been definitively linked with disease lesions at the cellular level (Work \& Aeby, 2006; Work et al., 2008). While standardized histological approaches allow investigations of disease lesions at the cellular level, in situ hybridization (ISH) approaches allow targeted localization of specific DNA and RNA sequences at the molecular scale (Levsky \& Singer, 2003). Specifically, fluorescence in situ hybridization (FISH) provides a powerful tool for simultaneous identification and visualization of bacteria within host tissues (Moter \& Gobel, 2000).

The application of FISH to coral samples has been complicated by the need for timeconsuming and labor-intensive processing, combined with specialized, and often expensive, microscopes and image processing software to separate probe fluorescence from high background tissue auto-fluorescence (Ainsworth et al., 2007; Pollock et al., 2011). Optimized FISH protocols have been developed to overcome some of these limitations, allowing researchers to target specific nucleic acid sequences in coral histological studies (Ainsworth et al., 
58 2006a; Ainsworth, Hoegh-Guldberg \& Leggat, 2008). Consequently, FISH approaches have

59 become a valuable tool to elucidate how microbial communities are spatially located within both

60 healthy and diseased coral tissues (Bythell et al., 2002; Webster et al., 2004; Lesser et al., 2004;

61 Ainsworth et al., 2006a; Ainsworth, Hoegh-Guldberg \& Leggat, 2008; Ainsworth \& Hoegh-

62 Guldberg, 2009; Apprill et al., 2009). For example, Bayer et al. (2013) recently employed FISH-

based techniques to identify abundant communities of Endozoicomonas-related bacteria residing

within healthy coral tissues, and Neave et al. (2016) showed that Endozoicomonas species, which can comprise as much as $90 \%$ of the microbiome, form cyst-like aggregations at the interface of

the epidermal and gastrodermal cell layers of Stylophora pistillata. Ainsworth et al. (2015)

identified a core coral microbiome using sequencing-based approaches and applied FISH

techniques to localize some members of this core microbiome within microhabitats of the coral

host. FISH also allows detection, identification and visualization of potential coral pathogens

(Ainsworth et al., 2007), which is important for studies of disease etiology and the development

of diagnostic tools for coral diseases (Pollock et al., 2011).

Autofluorescence associated with corals is the direct result of high densities of chlorophyll-containing dinoflagellates within the corals' gastrodermal layers and an abundance of fluorescent pigments, including green fluorescent protein-like molecules within coral cell layers (Salih et al 2000; Dove et al., 2001; Yokouchi et al., 2003; Ainsworth et al., 2006a).

Despite the demonstrated utility of direct localization and visualization of specific DNA and RNA targets within coral tissues and recent advances to overcome high levels of coral auto-

fluorescence, non-specific probe binding (i.e. erroneous hybridization of FISH probes to non- 
79 target structures leading to the detection of false positives) impedes the application of ISH and

80 FISH techniques to coral samples (Bythell et al., 2002; Ainsworth et al., 2006b; Apprill et al.,

81 2009). Clear and consistent guidelines and methodological criteria are therefore needed to

82 differentiate specific and non-specific probe binding. In this manuscript, we outline current

83 barriers to the application of FISH techniques to coral samples and provide clear guidelines to

84 help researchers and practitioners overcome these challenges.

Materials and Methods

87

88

\section{Sample collection}

Samples of healthy and white syndrome (WS) infected colonies of Acropora hyacinthus (i.e. colonies displaying diffuse, acute to sub-acute areas of tissue loss revealing white, intact skeleton; see Fig. 1) were collected from reefs near Lizard Island (14² $\left.40^{\prime} \mathrm{S}, 145^{\circ} 27^{\prime} \mathrm{E}\right)$ in the Northern sector of the Great Barrier Reef (GBR) on SCUBA (1-5 m depth), in September 2010, July 2011 and February 2012. At each sampling time point, $\sim 3 \mathrm{~cm}$ coral fragments were collected from each healthy colony $(n=4)$ and from each WS-infected colony (i.e., from the lesion-healthy tissue interface $[n=7]$ and from apparently healthy tissue $[n=3]$ approximately 10 $\mathrm{cm}$ away from the lesion). Coral fragments were placed in individual sterile bags underwater. Sampling was undertaken on Permit G11/34003.1 issued by the Great Barrier Marine Park Authority.

Fixation, decalcification and sectioning 
100 Within 15 minutes of collection, coral samples were placed in freshly prepared $4 \%$

101 paraformaldehyde (Electron Microscopy Sciences, USA), $10 \mathrm{mM}$ phosphate buffered saline

102 (PBS) solution at $4^{\circ} \mathrm{C}$. After 8-10 hrs, the paraformaldehyde solution was exchanged for a 1:1

103 solution of $10 \mathrm{mM}$ PBS and ethanol. Samples were rinsed with $10 \mathrm{mM}$ PBS and then embedded

104 in $1.5 \%$ agarose $\left(\sim 55\right.$ to $\left.60{ }^{\circ} \mathrm{C}\right)$ to maintain tissue conformation during the decalcification process.

105 Once the agarose was set, excess agarose was removed and a small hole was punched through to

106 the coral fragment to allow liquids to reach the sample. Agarose-embedded samples were placed

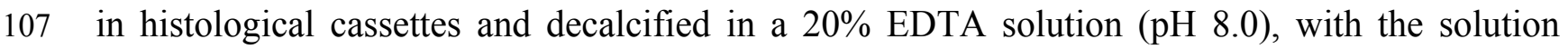

108 maintained at $4^{\circ} \mathrm{C}$ and exchanged approximately every 2 days for $2-3$ weeks. Following

109 decalcification, the agarose-embedded samples were rinsed in PBS, dehydrated sequentially in a

$11070 \%, 80 \%, 90 \%, 95 \%, 100 \%$ and $100 \%$ ethanol series for $60 \mathrm{~min}$ each, then processed through

111 three, 30 min xylene rinses and embedded in Paraplast paraffin wax. Paraffin-embedded samples

112 were serially sectioned at $4 \mu \mathrm{m}$ and collected on Superfrost Plus slides (Menzel, Germany).

113 Sections were dewaxed at $60^{\circ} \mathrm{C}$ prior to histological processing.

115 Histology

116 Prior to staining, one serial section from each sample was dewaxed in xylene ( $2 \times 3 \mathrm{~min})$ and 117 rehydrated through $3 \times 5 \min 100 \%$ ethanol, 1 × $5 \min 70 \%$ ethanol, and 1 x 2 min water washes. 118 Hydrated sections were counterstained in Mayer's Hematoxylin for 8 min, rinsed in tap water (1 119 x 20 dips), differentiated in Scott's tap water substitute for $30 \mathrm{sec}$ for bluing, rinsed in water (1 x $1202 \mathrm{~min}$ ) and stained in Eosin for $3 \mathrm{~min}$. Stained section were dehydrated through an ethanol series 
121 ( $1 \times 2$ min 70\% ethanol and $2 \times 5 \min 100 \%$ ethanol) and washed in xylene ( $2 \times 5$ min). Sections

122 were mounted in DPX mounting medium, observations were recorded using a Leica DMI 6000B

123 light microscope (Leica, Germany) and microphotograph images were processed using the LAS

124 imaging software (Leica, Germany).

125

126

127

128

129

130

131

132

133

134

135

136

137

138

139

140

141

Fluorescent in situ hybridisation (FISH)

Prior to staining, three serial tissue sections were dewaxed in xylene ( $2 \times 3 \mathrm{~min})$, dehydrated through $100 \%$ ethanol washes ( 3 x $5 \mathrm{~min}$ ) and air-dried. Dried sections were washed in a $0.2 \mathrm{M}$ $\mathrm{HCl}$ solution for $12 \mathrm{~min}$ and a $20 \mathrm{mM}$ Tris $\mathrm{HCl}$ solution ( $\mathrm{pH} \mathrm{8.0)}$ for $10 \mathrm{~min}$ at room temperature. To digest bacterial cellular membranes and allow easier probe penetration into tissues, sections were mounted in a proteinase $\mathrm{K}(50 \mu \mathrm{g} / \mathrm{ml}), 20 \mathrm{mM}$ Tris $\mathrm{HCl}$ solution $(\mathrm{pH} 8.0)$ for $5 \mathrm{~min}$ at 37 ${ }^{\circ} \mathrm{C}$ and rinsed in $20 \mathrm{mM}$ Tris $\mathrm{HCl}(\mathrm{pH} \mathrm{8.0)}$ prior to probe hybridisation. Oligonucleotide probes, including a probe targeting the $16 \mathrm{~S}$ rRNA gene (EUB338 mix: 5'-GCT GCC TCC CGT AGG AGT-3', 5'-GCA GCC ACC CGT AGG TGT-3', 5'-GCT GCC ACC CGT AGG TGT-3') and a nonsense, negative control probe (NonEUB338: 5'-ACA TCC TAC GGG AGG C-3'), were labeled with the Cy3 flurochrome (Thermo Fisher Scientific, Germany) (Wallner, Amann \& Beisker, 1993; Daims et al., 1999). Tissue sections were covered with hybridization buffer (30\% v/v formamide, $0.9 \mathrm{M} \mathrm{NaCl}, 20 \mathrm{mM}$ Tris- $\mathrm{HCl}$ ( $\mathrm{pH} 8.0$ ), 0.01\% SDS), oligonucleotide probes were added to a final concentration of $25 \mathrm{ng} \mu \mathrm{l}^{-1}$, and samples were incubated at $46^{\circ} \mathrm{C}$ for 1.5 hours. Sections were washed in $50 \mathrm{ml}$ Falcon tubes containing preheated wash buffer $(0.112 \mathrm{M}$ $\mathrm{NaCl}, 20 \mathrm{mM}$ Tris- $\mathrm{HCl}$ (pH 8.0), 0.01\% SDS, 5mM EDTA) in a water bath at $48^{\circ} \mathrm{C}$ for $10 \mathrm{~min}$. 
142 Following washing, sections were immediately soaked in cold, filtered water for 10 seconds to 143 remove excess salts, air dried and mounted in Citifluor AF1 (ProScitech, Australia). As a 144 negative control, one serial tissue section was processed as described above, but no 145 oligonucleotide probe was added. To detect true and false binding simultaneously, one serial 146 section was processed with the Cy3-labelled EUB338 mix probes as described above, and a Cy5labelled NonEUB338 probe applied to the same section. An LSM710 confocal laser scanning microscope (Carl Zeiss, Germany) combined with spectral emissions profiling was used to visualize tissue-associated, FISH-labeled bacterial communities, as described by Ainsworth et al. (2006). Detection of the Cy3 fluorochrome label was in the emission range $519-580 \mathrm{~nm}$ and the target signal was recorded at $561 \mathrm{~nm}$. Auto-fluorescence detection and spectral removal included emission ranges of $407-486 \mathrm{~nm}$ for removal of coral tissue autofluorescence and $627-704 \mathrm{~nm}$ for removal of dinoflagellates (Symbiodinium) autofluorescence. Micrographs of bacterial communities associated with coral tissue sections were processed using Zen 2009 software (Zeiss, Germany). The linear unmixing function of the Zen 2009 software (Zeiss, Germany) was utilized when multiple probes were visualized simultaneously.

\section{Trouble shooting approaches}

To determine if the sequence of the oligonucleotide probe contributes to non-specific binding, three probes were assessed: EUB338 mix probes, NonEUB338 and a Vib-GV ( 5'-AGG CCA CAA CCT CCA AGT AG-3'; Giuliano et al., 1999). To determine if the fluorochrome attached to the oligonucleotide probe affects non-specific binding, three flurochromes were assessed: Atto 
163647 (excitation $\lambda=645$, emission $\lambda=669$ ) Cy3 (excitation $\lambda=548$, emission $\lambda=561$ ) and

164 Cy5 (excitation $\lambda=647$, emission $\lambda=665$ ) (i.e. Cy3-labeled EUB338 mix, Cy3-labeled 165 NonEUB338, Cy5-labeled NonEUB338 and Atto 647-labelled Vib-GV). To assess the utility of 166 incorporating hybridising agents in the FISH workflow to avoid non-specific binding, "Blocking 167 Reagent" (Roche, Germany) was added to the hybridisation buffer (30\% formamide, $0.9 \mathrm{M}$ $168 \mathrm{NaCl}, 20 \mathrm{mM}$ Tris-HCl with adjusted $\mathrm{pH} 8.0,0.01 \% \mathrm{SDS}, 10 \%$ "Blocking Reagent" with maleic 169 acid buffer), alongside Cy3-labelled NonEUB338 probe.

\section{Results and Discussion} highlighted in FISH-labeled sections of healthy samples of Acropora hyacinthus from Lizard Island in the northern Great Barrier Reef (GBR) (Fig. 2). Under fluorescence excitation light, coral tissues targeted with probes for Bacteria (EUB338) show multiple strongly fluorescent cellular structures within anatomical features of coral polyps (e.g., mesenterial filaments, Fig. 2A), suggesting the presence of targeted bacteria within gastrodermal and epidermal cells. However, direct comparison with serial sections targeted with nonsense negative control probes (NonEUB338) (i.e. probes specifically designed to detect non-target binding) (Fig. 2B) highlights strong non-specific binding of both probes to granular gland cells within the 
183 distributed throughout the gastrodermis, including in regions of coenosarc, stomodeum and 184 mesenterial filaments, where secretions are released into the corals' coelenteron (gastrovascular

185

186

187

cavity) to aid extracellular digestion of prey (Galloway et al., 2007). The lack of granular cell fluorescence in probe-free, negative control sections (Fig. 2C) indicate that these false positives are caused by non-specific binding of the oligonucleotide probes rather than auto-fluorescence. Granular gland cells within the gastrodermis appear as pink aggregations in hematoxylin and eosin (H\&E) stained histological sections (Harrison 1980; Fig. 2D). Due to their strong fluorescence signal in FISH images (Fig. 2A,B,E), combined with their spherical shape and similar size to bacteria (approximate diameter $=0.5 \mu \mathrm{m}$ ), non-specific binding of granular gland cells can easily be confused with true binding to small cocci bacterial cells.

Spirocysts, which are a type of cnidae comprised of a single-walled capsule containing a tightly coiled tubule bearing microtubules (Galloway et al., 2007), were another common site for non-specific FISH probe binding. Spirocysts were frequently detected in the epidermal layer and were particularly prevalent in the coenosarc and tentacles (Fig. 2F,G). Unlike granular gland cells, spirocysts can be easily differentiated from bacterial aggregations due to their coiled tubules (Fig. 2F,G). However, this distinction may not be obvious to the untrained practitioner. Non-specific binding of FISH probes to common cellular structures (granular gland cells and spirocysts, in particular) within coral tissues highlights the importance of including non-target (i.e. NonEUB338) probe controls and extensive familiarization with coral cellular structure to differentiate true positive signals from false positives.

Common approaches designed to avoid non-specific binding failed to reduce non- 
204 specific fluorescent signals generated by false probe binding to spirocysts and granular gland 205 cells. The incorporation of alternative oligonucleotide probes, which targeted different $16 \mathrm{~S}$ rRNA sequences with different hybridization kinetics and efficiencies (competitor probes), also

207

yielded non-specific hybridization to granular gland cells (Fig. 2C) and spirocysts (Fig. 3). Increased probe hybridization stringencies through higher formamide concentrations in the hybridization buffers, plus higher stringency post-hybridization washing as recommended by Wallner, Amann \& Beisker (1993), also failed to reduce the strong fluorescent signal associated with these cellular structures. Furthermore, the application of commercially available blocking solutions, which are specifically designed to prevent non-specific binding, also failed to prevent non-specific binding of oligonucleotide probes to granular gland cell and spirocysts (Fig. 3D). Difficulties discriminating true detection of bacterial cells from non-specific binding to non-target cellular structures is demonstrated in tissue sections of Acropora hyacinthus affected by a WS disease (Fig. 2H). Coral-associated microbial aggregates (CAMAs) can be observed within the calicoblastic layer of healthy tissues sampled from WS diseased colonies $(n=3)$ and probed with the EUB338 probe (Fig. 2H). CAMAs have been identified in healthy tissues of many coral species (Work and Aeby 2014), although their exact functional role is unknown and their influence on a coral's position along a healthy-diseased continuum needs further exploration. Non-specific binding to granular gland cells was also observed within gastrodermal cells that were in the vicinity of a bacterial aggregate, and could be mistaken for a true positive without detailed understanding of coral cellular structures (Fig. 2H). True positive detection of bacterial assemblages and individual bacterial cells were observed in all regions $(n=6)$ of 
225 sections from actively progression WS lesions (Fig. 2I).

Recommendations to avoid common pitfalls

The inability to prevent non-specific binding of oligonucleotide probes to cellular structures within coral tissues represents a major challenge for accurate identification of specific bacterial targets. However, by taking into account the issues highlighted above and the recommendations laid out below, these challenges can be overcome.

- Combining appropriate microscope hardware with advanced image acquisition software significantly improves detection of bacterial cells within coral tissues. Laser confocal scanning microscopes (LSCM) provide the ideal platform for optimized image resolution, fluorescence signal acquisition, and removal of non-specific background auto-fluorescence. While standard fluorescence microscopes can be used to visualize coral samples for some applications (e.g. coral mucus-associated microorganisms), high sample auto-fluorescence often confounds coral FISH studies. Unfortunately, LSCMs are relatively expensive, which limits access for some researchers, but many of the suggestions outlined below should prove helpful, regardless of the microscope/software available.

- Selecting an appropriate fluorochrome with an emission spectrum distinct from that of coral tissues (e.g. background green fluorescent proteins) and Symbiodinium cells (i.e. background fluorescence in red and far red due to the presence of chlorophyll) is an important consideration (Ainsworth et al., 2006a). Certain fluorochromes (e.g. FITC) are not 
245 ideal for visualizing targets within coral tissues, while others (i.e. Cy3, Cy5 and Atto647)

246 are commonly used for coral samples. However, it is important to note that few, if any,

247 fluorochromes provide emission spectra completely distinct from that of coral tissue and

248 Symbiodinium auto-fluorescence.

249 - When using microscopes that allow spectral profiling at the pixel scale, comparison of

250 background emission spectra and intensity with that of potential positive signals (i.e. probe

251 binding) can greatly improve differentiation between background fluorescence and true 252 probe binding.

253

254

255

256

257

258

259

260

261

262

- Alternative approaches to FISH, such as catalyzed reporter deposition FISH (CARD-FISH) that which increase probe emission signal intensity, can aid in the differentiation of target versus non-target fluorescence. Such approaches have been widely used in other environmental samples (Pernthaler, Pernthaler \& Amann, 2002) and are now being successfully used for corals (see examples in Ainsworth et al 2006a; Bayer et al., 2013; Neave et al 2016).

- Serial sections should be visualized using both FISH and traditional staining (e.g. H\&E stain or Trichrome stains) to identify and localize granular gland cells within the gastrodermal cell layer, particularly within the glandular band of mesenterial filaments, and spirocysts within epidermal cell layers, particularly in coenosarc and stomodeum regions of the polyp.

- A nonsense probe representing a true negative control must be applied to serial tissue sections (or on the same section) to help distinguish specific probe binding to target bacterial populations from non-specific probe binding to coral cellular structures (Wallner, 
266

267

268

269

270

271

272

273

Amann \& Beisker, 1993).

- Familiarity with coral tissue structures is imperative to distinguish morphological characteristics, such as size and shape that differentiate bacteria from coral tissue structures, including spirocysts and granular gland cells that are prone to non-specific probe binding (Posch et al., 1997, 2009). Undertaking practical courses that focus on histological analysis of cellular structures, particularly focused on coral tissues, can aid in the familiarization process, along with close collaborative networks with practitioners already trained in this area.

Non-specific probe binding constitutes a significant impediment to FISH-based detection of coral-associated bacterial communities. However, the inclusion of appropriate control measures combined with observational rigor can greatly increase the ability of practitioners to accurately distinguish non-specific probe binding and host auto-fluorescence from true positive bacterial signals. Detailed approaches for the application of FISH to both healthy and diseased corals are summarized in supplementary Fig. S1 and further details of pitfalls and possible solutions are summarized in Table S1. Following these recommendations will allow practitioners to avoid confusion associated with non-specific binding and allow FISH techniques to be employed to their full potential in studies of coral tissues.

\section{Acknowledgements}

The authors would like to thank Dr. Jean-Baptiste Raina and Dr. Yui Sato for their logistical help during the project. 
287

288

289

290

291

292

293

294

295

296

297

298

299

300

301

302

303

304

305

306

307

\section{References}

Ainsworth TD., Fine M., Blackall LL., Hoegh-Guldberg O. 2006a. Fluorescence In Situ Hybridization and Spectral Imaging of Coral-Associated Bacterial Communities. Applied and Environmental Microbiology 72:3016-3020. DOI: 10.1128/AEM.72.4.30163020.2006 .

Ainsworth TD., Kvennefors EC., Blackall LL., Fine M., Hoegh-Guldberg O. 2006b. Disease and cell death in white syndrome of Acroporid corals on the Great Barrier Reef. Marine Biology 151:19-29. DOI: 10.1007/s00227-006-0449-3.

Ainsworth TD., Kramasky-Winter E., Loya Y., Hoegh-Guldberg O., Fine M. 2007. Coral disease diagnostics: what's between a plague and a band? Applied and environmental microbiology 73:981-92. DOI: 10.1128/AEM.02172-06.

Ainsworth TD., Krause L., Bridge T., Torda G., Raina J-B., Zakrzewski M., Gates RD., PadillaGamiño JL., Spalding HL., Smith C., Woolsey ES., Bourne DG., Bongaerts P., HoeghGuldberg O., Leggat W. 2015. The coral core microbiome identifies rare bacterial taxa as ubiquitous endosymbionts. The ISME Journal:1-14. DOI: 10.1038/ismej.2015.39.

Ainsworth T., Hoegh-Guldberg O. 2009. Bacterial communities closely associated with coral tissues vary under experimental and natural reef conditions and thermal stress. Aquatic Biology 4:289-296. DOI: 10.3354/ab00102.

Ainsworth TD., Hoegh-Guldberg O., Leggat W. 2008. Imaging the fluorescence of marine invertebrates and their associated flora. Journal of microscopy 232:197-9. DOI: 10.1111/j.1365-2818.2008.02089.x. 
308

309

310

311

312

313

314

315

316

317

318

319

320

321

322

323

324

325

326

327

328

Apprill A., Marlow HQ., Martindale MQ., Rappé MS. 2009. The onset of microbial associations in the coral Pocillopora meandrina. The ISME Journal 3:685-699. DOI: 10.1038/ismej.2009.3.

Bayer T., Neave MJ., Alsheikh-Hussain A., Aranda M., Yum LK., Mincer T., Hughen K., Apprill A., Voolstra CR. 2013. The Microbiome of the Red Sea Coral Stylophora pistillata Is Dominated by Tissue-Associated Endozoicomonas Bacteria. Applied and Environmental Microbiology 79:4759-4762. DOI: 10.1128/AEM.00695-13.

Bourne DG., Garren M., Work TM., Rosenberg E., Smith GW., Harvell CD. 2009. Microbial disease and the coral holobiont. Trends in microbiology 17:554-62. DOI: 10.1016/j.tim.2009.09.004.

Bourne DG., Muirhead A., Sato Y. 2011. Changes in sulfate-reducing bacterial populations during the onset of black band disease. The ISME journal 5:559-564. DOI: 10.1038/ismej.2010.143.

Bythell JC., Barer MR., Cooney RP., Guest JR., O’Donnell AG., Pantos O., Le Tissier MDA. 2002. Histopathological methods for the investigation of microbial communities associated with disease lesions in reef corals. Letters in Applied Microbiology 34:359-364. DOI: 10.1046/j.1472-765X.2002.01097.x.

Daims H., Brühl A., Amann R., Schleifer KH., Wagner M. 1999. The domain-specific probe EUB338 is insufficient for the detection of all Bacteria: development and evaluation of a more comprehensive probe set. Systematic and applied microbiology 22:434-44. DOI: 10.1016/S0723-2020(99)80053-8. 
329 Dove SG., Hoegh-Guldberg O., Rangananthan S. 2001. Major colour patterns of reef-building 330 corals are due to a family of GFP-like proteins. Coral Reefs 19:197-204. DOI: 10.1007/PL00006956

332

Galloway SB., Woodley CM., McLaughlin SM., Work TM., Bochsler VS., Meteyer CU., Sileo L., Peters EC., Kramarsky-Winters E., Morado JF., Parnell PG., Rotstein DS., Harley RA., Nicholson J., Reynolds TL. 2007. Coral Disease and Health Workshop: Coral Histopathology II. NOAA Technical Memorandum NOS NCCOS 56 and NOAA Technical Memorandum CRCP 4, National Oceanic and Atmospheric Administration, Silver spring.

Giuliano., De Domenico M., De Domenico E., Höfle., Yakimov. 1999. Identification of Culturable Oligotrophic Bacteria within Naturally Occurring Bacterioplankton Communities of the Ligurian Sea by 16S rRNA Sequencing and Probing. Microbial ecology 37:77-85. DOI: 10.1007/s002489900

Lesser MP., Mazel CH., Gorbunov MY., Falkowski PG. 2004. Discovery of symbiotic nitrogenfixing cyanobacteria in corals. Science (New York, N.Y.) 305:997-1000. DOI: 10.1126/science.1099128.

Levsky JM., Singer RH. 2003. Fluorescence in situ hybridization: past, present and future. Journal of cell science 116:2833-8. DOI: 10.1242/jcs.00633.

Moter A., Gobel UB. 2000. Fluorescence in situ hybridization (FISH) for direct visualization of microorganisms. J Microbiol Methods 41:85-112. DOI: 10.1016/S0167-7012(00)00152-4

Neave M., Rachmawati R., Xun L., Michell C., Bourne DG., Apprill A., Voolstra C. 2016. 
350

351

352

353

354

355

356

357

358

359

360

361

362

363

364

365

366

367

368

369

370

Differential specificity between closely related corals and abundant Endozoicomonas endosymbionts across global scales. ISME Journal DOI:10.1038/ismej.2016.95

Pernthaler A., Pernthaler J., Amann R. 2002. Fluorescence in situ Hybridization and Catalyzed Reporter Deposition for the Identification of Marine Bacteria. Applied and Environmental Microbiology 68:3094-3101. DOI: 10.1128/AEM.68.6.3094-3101.2002.

Pollock FJ., Morris PJ., Willis BL., Bourne DG. 2011. The Urgent Need for Robust Coral Disease Diagnostics. PLoS Pathog 7:e1002183. DOI: 10.1371/journal.ppat.1002183.

Posch T., Pernthaler J., Alfreider A., Psenner R. 1997. Cell-specific respiratory activity of aquatic bacteria studied with the tetrazolium reduction method, cyto-clear slides, and image analysis. Applied and Environmental Microbiology 63:867-873.

Posch T., Franzoi J., Prader M., Salcher M. 2009. New image analysis tool to study biomass and morphotypes of three major bacterio-plankton groups in an alpine lake. Aquatic Microbial Ecology 54:113-126. DOI: 10.3354/ame01269

Rohwer F., Seguritan V., Azam F., Knowlton N. 2002. Diversity and distribution of coralassociated bacteria. Marine Ecology Progress Series 243:1-10. DOI: $10.3354 / \operatorname{meps} 243001$.

Rosenberg E., Koren O., Reshef L., Efrony R., Zilber-Rosenberg I. 2007. The role of microorganisms in coral health, disease and evolution. Nature reviews. Microbiology 5:355-62. DOI: 10.1038/nrmicro1635.

Salih A., Larkum A., Cox G., Kuhl M., Hoegh-Guldberg O. 2000. Fluorescent pigments in corals are photoprotective. Nature 408:850-853. DOI: $10.1038 / 35048564$ 
371 Wallner G., Amann R., Beisker W. 1993. Optimizing fluorescent in situ hybridization with

372

373

374

375

376

377

378

379

380

381

382

383

384

385

386

387

388

389
rRNA-targeted oligonucleotide probes for flow cytometric identification of microorganisms. Cytometry 14:136-43. DOI: 10.1002/cyto.990140205.

Webster NS., Smith LD., Heyward AJ., Watts JEM., Webb RI., Blackall LL., Negri AP. 2004. Metamorphosis of a Scleractinian Coral in Response to Microbial Biofilms. Applied and Environmental Microbiology 70:1213-1221. DOI: 10.1128/AEM.70.2.1213-1221.2004.

Work TM., Richardson LL., Reynolds TL., Willis BL. 2008. Biomedical and veterinary science can increase our understanding of coral disease. Journal of Experimental Marine Biology and Ecology 362:63-70. DOI: 10.1016/j.jembe.2008.05.011.

Work TM., Aeby GS. 2006. Systematically describing gross lesions in corals. Diseases of aquatic organisms 70:155-60. DOI: 10.3354/dao070155

Work TM., Aeby GS. 2014. Microbial aggregates within tissues infect a diversity of corals throughout the Indo-Pacific. Marine Ecology Progress Series 500:1-9. DOI: $10.3354 /$ meps 10698

Yokouchi H., Takeyama H., Miyashita H., Maruyama T., Matsunaga T. 2003. In situ identification of symbiotic dinoflagellates, the genus Symbiodinium with fluorescencelabelled rRNA-targeted oligonucleotide probes. Journal of Microbiologial Methods 53:327-334. DOI: $\underline{10.1016 / \mathrm{S} 0167-7012(02) 00250-6}$ 

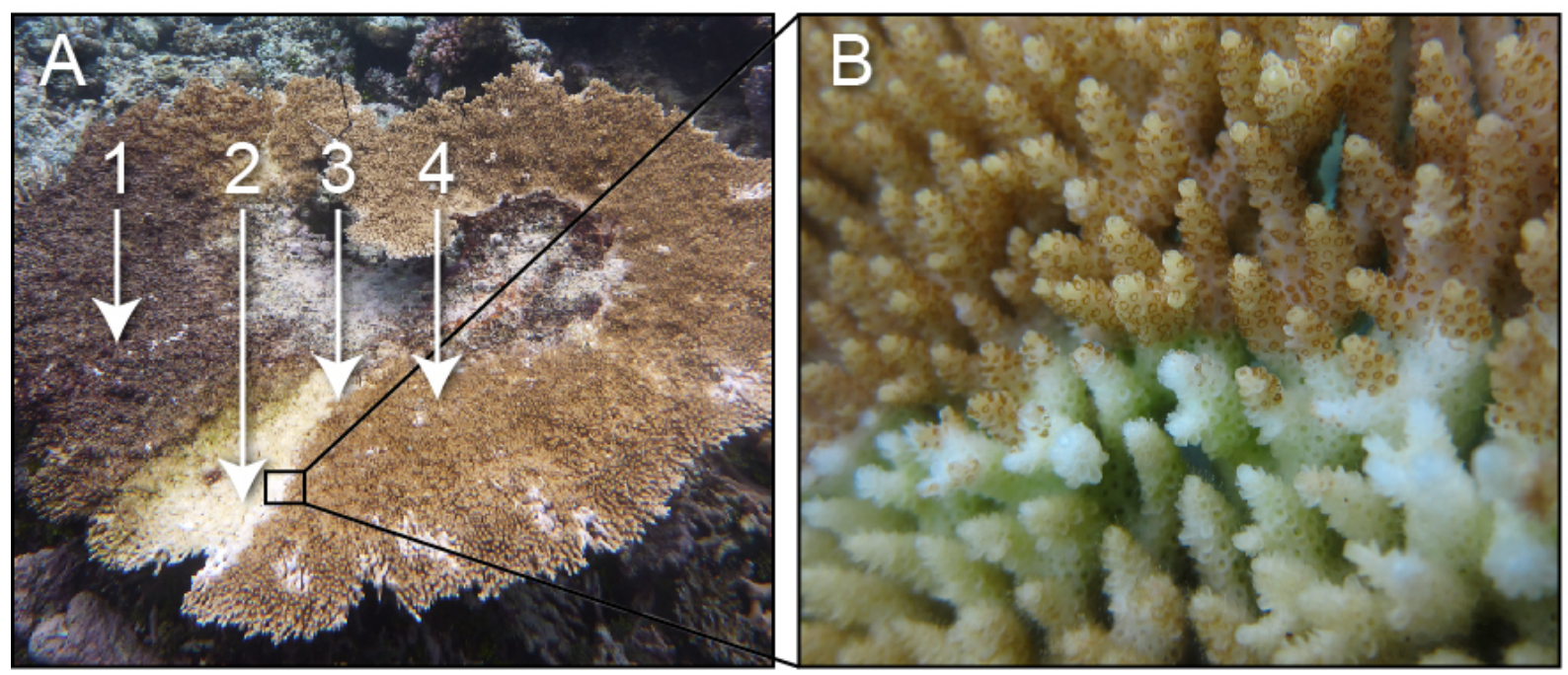

Figure 1. Characteristic field appearance of a white syndrome (WS) on a colony of the coral Acropora hyacinthus from reefs near Lizard Island (14\%40'S, $\left.145^{\circ} 27^{\prime} \mathrm{E}\right)$ in the Northern sector of the Great Barrier Reef (GBR): (A) WS lesion on a coral colony with numbers and arrows displaying (1) dead coral skeleton overgrown with algae, (2) recently exposed coral skeleton prior to algal overgrowth, (3) actively progressing lesion boundary where samples derived for this study were taken, (4) healthy tissue ahead of the lesion and from which samples were also derived. (B) Close up image of lesion boundary displaying diffuse, acute to sub-acute areas of tissue loss revealing white, intact skeleton. 

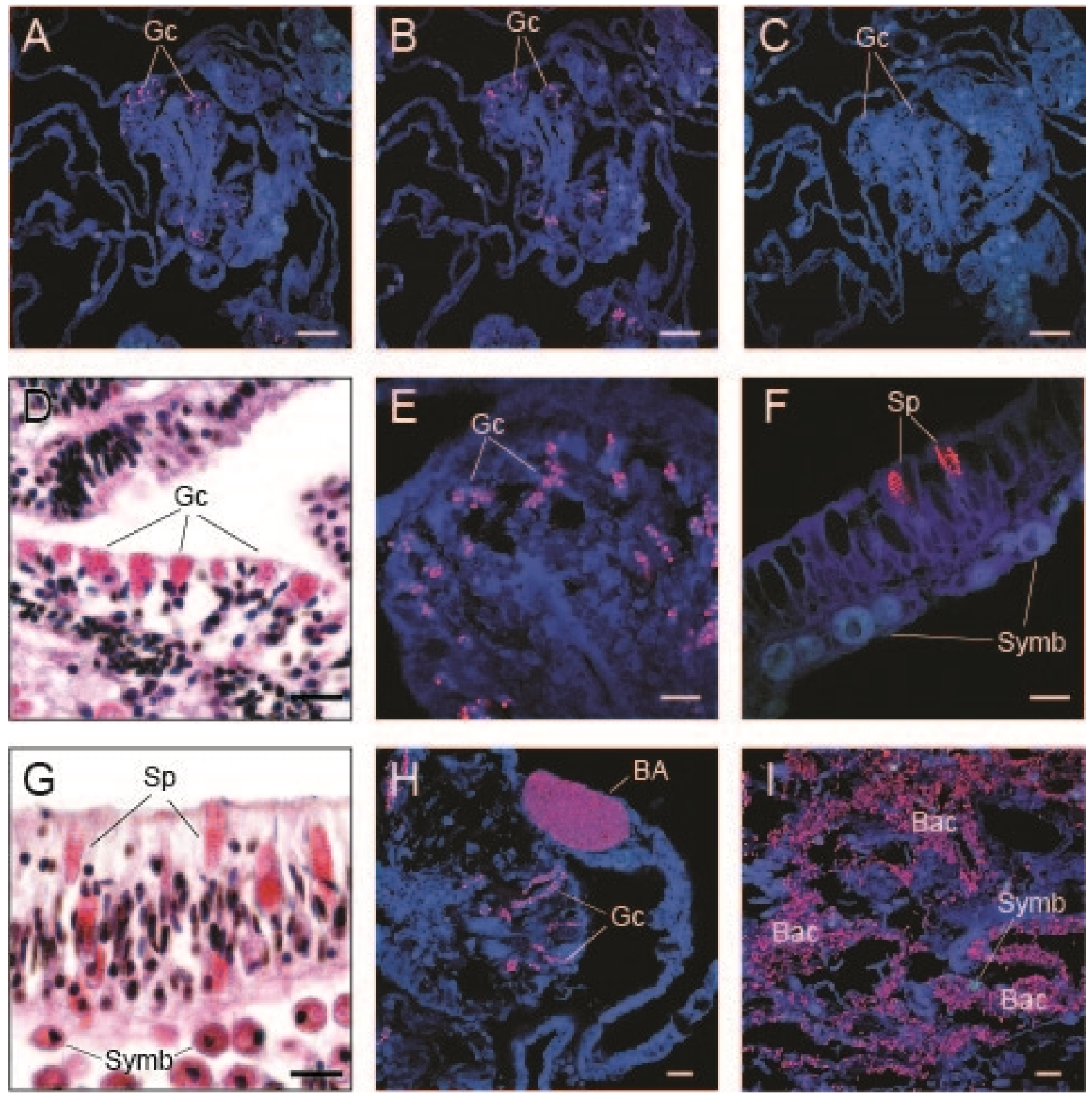

Figure 2. Detection and characterization of specific and non-specific fluorescence in situ

hybridization (FISH) probe binding to target bacteria (BA and Bac), granular gland cells (Gc), and spirocysts (Sp) using Cy3-labelled FISH probes (A-C,E,F,H,I) and Hematoxylin and Eosin

407 (H\&E) staining of coral tissue sections (D,G). Non-specific binding of EUB338 (A) and 
408 nonEUB338 (B) FISH probes to granular gland cells and lack of auto-fluorescence of these 409 structures in probe-free treatments (C) is demonstrated through serial tissue sections. Detailed 410 granular gland cell morphology within the gastrodermis is shown in H\&E stained (D) and 411 EUB338 FISH-hybridized (E) tissue sections. Non-specific binding of EUB338 FISH probes to 412 spirocysts within epidermal cells (F) was detected in tissue sections and was particularly 413 prevalent in coenosarc and tentacle regions of polyps. Detailed spirocyst morphology is shown 414 through H\&E staining $(\mathrm{G})$. A bacterial aggregate within the calicoblastic layer is shown near to 415 non-specific binding signals of granular gland cells $(\mathrm{H})$ in healthy coral tissues hybridized with 416 EUB338 FISH probes. Bacteria assemblages were detected within necrotic tissues associated 417 with WS disease using EUB338 FISH probes (I). Scale bars represent $50 \mu \mathrm{m}$ in A - C and $10 \mu \mathrm{m}$ 418 in D - I. Abbreviations: Gc, granular gland cell; Sp, spirocysts; Symb, Symbiodinium; BA, 419 bacterial aggregation; Bac, bacterial assemblages. 

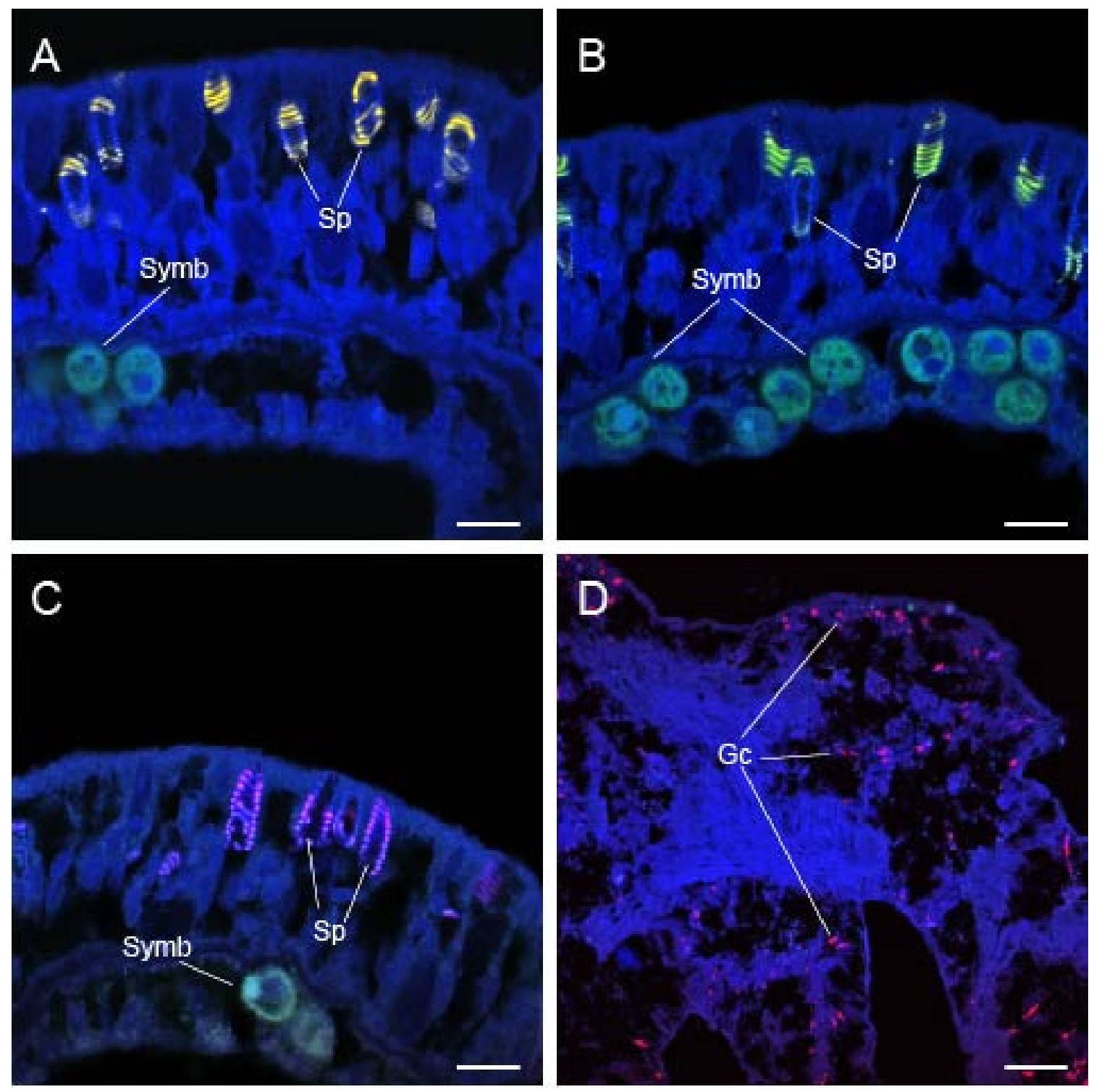

Figure 3. The application of common approaches designed to ameliorate non-specific fluorescence in situ hybridization (FISH) probe binding failed to inhibit hybridization to granular

424 gland cells (Gc) and spirocysts (Sp). Cy3 (A), Cy5-labelled NonEUB338 (B) and Atto 647-

425 labelled Vib-GV (C) FISH probes all hybridized to spirocysts. Blocking solution also failed to 426 prevent non-specific binding of oligonucleotide probes to granular gland cells (D). Scale bars 427 represent $100 \mu \mathrm{m}$ in $\mathrm{A}-\mathrm{C}$ and $50 \mu \mathrm{m}$ in D. Abbreviations: Gc, granular gland cell; $\mathrm{Sp}$, 428 spirocysts; and Symb, Symbiodinium 
Coral Tissue Sample Preparation

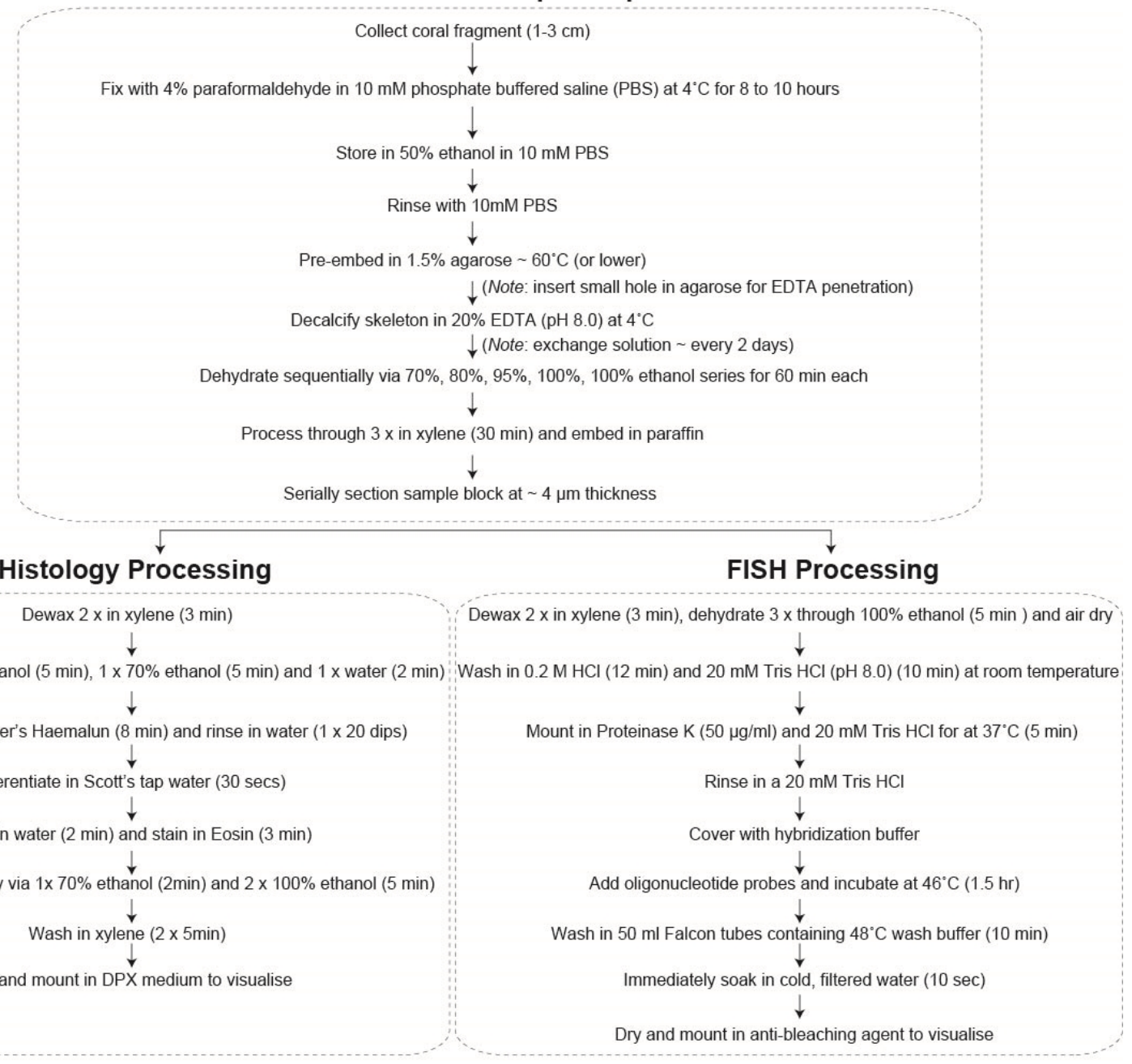

431 Supplementary Figure S1. Schematic flow chart detailing the protocol to process coral samples

432 for both histological and FISH based visualization of coral tissue structure and identification of

433 bacterial communities associated with coral tissues. 
45Supplementary Table S1. Identified pitfalls and potential solutions to overcome challenges of applying FISH approaches to coral tissues

436

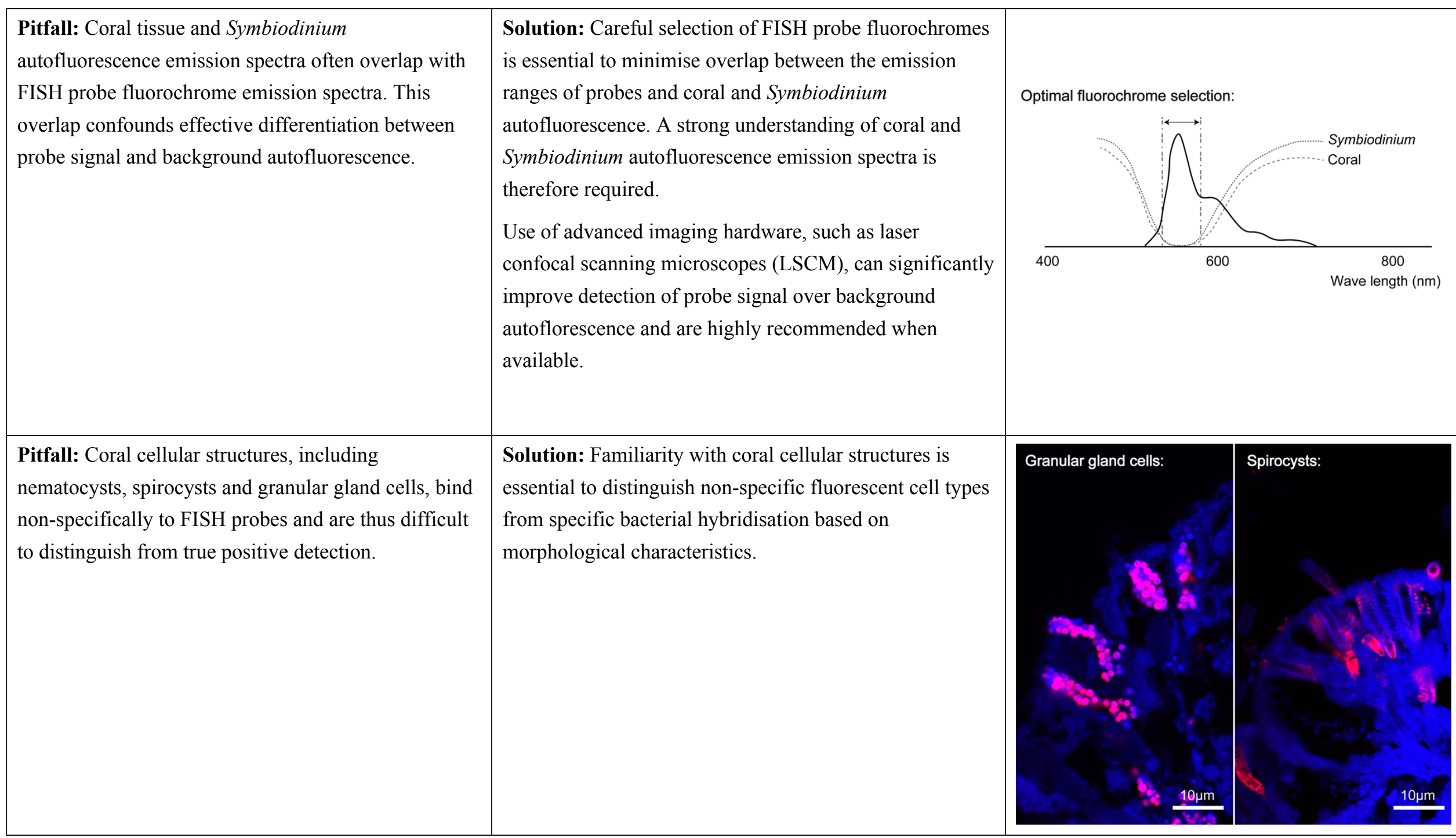




\begin{tabular}{|c|c|c|}
\hline $\begin{array}{l}\text { Pitfall: Low fluorescent signal due to low copy } \\
\text { number of target rRNA molecules can make it } \\
\text { difficult to visualise bacterial cells in coral tissue } \\
\text { sections. }\end{array}$ & $\begin{array}{l}\text { Solution: Florescent signal amplification techniques such } \\
\text { as CARD-FISH can increase signal intensity when target } \\
\text { rRNA copy numbers are low. These approaches have } \\
\text { proven successful in coral FISH studies (see Bayer et al } \\
2013 \text {, Neave et al 2016). }\end{array}$ & \\
\hline $\begin{array}{l}\text { Pitfall: The use of nonsense probes to detect non- } \\
\text { specific binding can be problematic as the } \\
\text { nematocysts, spirocysts and granular gland cells bind } \\
\text { the probe. During a 2-step process of hybridising with } \\
\text { a non-sense probe labelled with one flourochrome and } \\
\text { then binding with another specific target probe } \\
\text { labelled with a different flourochrome, these cellular } \\
\text { structures hybridise to both probes. }\end{array}$ & $\begin{array}{l}\text { Solution: Nonsense probes should still always be applied } \\
\text { to tissue sections to detect and diagnose non-specific } \\
\text { probe binding. However, familiarity with coral cellular } \\
\text { structures is essential to distinguish these non-specific } \\
\text { fluorescent cell types from targeted probe signals. }\end{array}$ & 2. Antisence probe \\
\hline
\end{tabular}




\begin{tabular}{|l|l|}
\hline $\begin{array}{l}\text { Pitfall: While the use of advanced imaging hardware } \\
\text { (such as a LSCM) combined with florescent signal } \\
\text { amplification techniques (such as CARD-FISH) is } \\
\text { recommended, such approaches have the potential to } \\
\text { confound the specific detection of bacteria in coral } \\
\text { tissues. For example, the signal intensity of non- } \\
\text { specific binding to spirocysts and granular gland cells }\end{array}$ & $\begin{array}{l}\text { Solution: Care must be exercised when using florescent } \\
\text { advanced imaging hardware that allows spectral profiling } \\
\text { at the pixel scale. Again, familiarity with coral cellular } \\
\text { structures is essential to } \\
\text { ensure all detected signals are from bacteria specific } \\
\text { targets and not background non-specific cellular much greater than that of specific probe } \\
\text { structures. }\end{array}$ \\
$\begin{array}{l}\text { colour to be assigned to these false positives so that } \\
\text { they can be disregarded. The application of CARD- }\end{array}$ \\
$\begin{array}{l}\text { FISH can intensify true positive signals to a level } \\
\text { comparable to those associated with non-specific }\end{array}$ \\
binding making intensity-based differentiation \\
difficult.
\end{tabular}

